\title{
INÁ KAKITANI
}

\section{OBSERVAÇÕES PRELIMINARES}

\section{SOBRE A PARIDADE DE ANOPHELES (KERTESZIA) CRUZII}

Dissertação de Mestrado apresentada à Faculdade de Saúde Pública da Universidade de São Paulo, Departamento de Epidemiologia, para obtenção do título de Mestre em Saúde Pública.

Orientador: Prof. Dr. Almério de Castro Gomes

SÃo PAULO

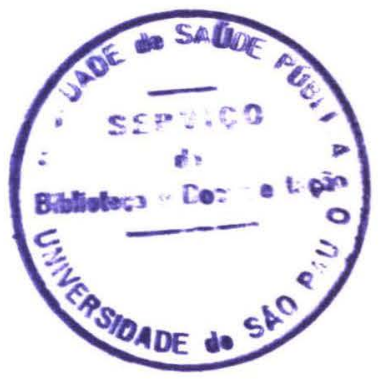

1992 


\section{AGRADECIMENTOS}

Sou grata aos vários colegas do Departamento de Epidemiologia e do Serviço de Biotério da Faculdade de Saúde Pública da Universidade de São Paulo pelo incentivo e contribuição à elaboração deste trabalho. Em especial ao Professor Almério de Castro Gomes pela valiosa orientação e ao Professor Oswaldo Paulo Forattini pelas sugestões e revisão do manuscrito.

Ao Conselho Nacional de Pesquisa (CNPq), pelo apoio financeiro durante parte da execução deste trabalho. 


\section{RESUMO}

Este trabalho consistiu em observaçōes de campo e de laboratório, sendo que a primeira foi desenvolvida na localidade da Fazenda Folha Larga, município de Cananéia, Estado de São Paulo. As capturas foram feitas nos ambientes extra e peridomiciliares com isca humana em horário de pico máximo de atividade hematófaga de Anopheles (Kerteszia) cruzii. Resultados preliminares obtidos em campo objetivaram determinar a paridade, enquanto que sob condições laboratoriais procurou-se conhecer a duração do ciclo gonotrófico, ambos considerados parâmetros implicados na determinação da capacidade vetora de $A n$. cruzii. Assim pois, das 631 fêmeas dissecadas, 90,49\% revelaram-se nulíparas e somente 9,50\% uníparas, mostrando que a maior parte da população era constituida de individuos jovens e sem haver diferença significativa quanto a proporção de fêmeas uníparas nos diversos ambientes. No laboratório trabalhou-se com 1.158 larvas dessa espécie, oriundas de aproximadamente 600 bromélias. O período de desenvolvimento larvário foi de aproximadamente 40 dias. Desse material, 283 fêmeas foram alimentadas com sangue humano, sendo que $50 \%$ conseguiu o seu desenvolvimento folicular completo com um único repasto sangüíneo. Outras 25 fêmeas, não receberam alimentação sangüinea $e$, quando dissecadas, todas apresentaram o seu primeiro folículo no estágio II de Christophers e Mer, provavelmente pela falta de estímulo sangüíneo. Além do mais, determinou-se que o tempo médio entre a alimentação sangǘnea e a oviposição foi de 6 a 7 dias. Em vista disso, as observações preliminares, possibilitam considerar esta espécie com razoável capacidade vetora, apesar da baixa longevidade, pois esta é provavelmente, compensada pela alta densidade. 


\section{SUMMARY}

This study consisted on field and laboratory observations. The former was developed at Folha Larga Farm, Cananéia County, São Paulo State. Collections were made in extra and peridomiciliary environments with human bait during the maximum peak of Anopheles cruzii blood feeding activity. Preliminary results obtained in the field, led to the determination of parity, and those developed in the laboratory led to the determination of the gonotrophic cycle length, both considered as involved parameters in the determination of vector capacity. From 631 females dissected, $90.49 \%$ were nulliparous, and $9.0 \%$ uniparous, showing that the greater part of the population was composed of young females. No significant difference between the proportion of uniparous females in the extra and peridomiciliary environment was found. At the laboratory 1,158 larvae of Ancruzii from 600 bromelia were examined.. The period of larval development was about 40 days. From this material, 283 females were fed with human blood, 50\% of them reached complete follicular development with a single bloodmeal, showing the first follicular in the Christophers and Mer's stages II, probably because of the lack of blood stimulus. Besides, was determined that the average time between bloodmeal and oviposition was 6 to 7 days. As a result of these preliminary observations was possible to consider this species as a vector with positive capacity, inspite of its low longevity, that could be probably compensated by its high density. 


\section{INDICE}

Pág.

INTRODUÇÃo. ............................... 1

Estado atual e objetivo................... 6

MATERIAL E MÉTODO........................ 8

I - Procedimento em Campo..................... 9

1 - Formas adultas....................... 9

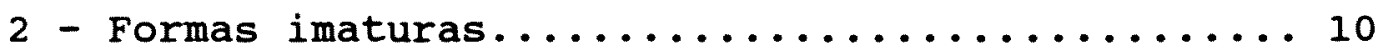

II - Procedimento em Laboratório................ 12

1 - Formas adultas...................... 12

2 - Desenvolvimento das formas imaturas.......... 14

RESULTADOS............................... 15

I - Observações de Campo (Adultos) .............. 16

II - Observações de Laboratório.................. 26

1 - Periodo de Desenvolvimento das formas imaturas. 26

2 - Desenvolvimento das formas adultas.......... 27

DISCUSSÃo E COMENTÁRIOS.................... 31

REFERENCIAS BIBLIOGRÁFICAS................... 39 
INTRODUÇÃO 
Dentre as doenças veiculadas por artrópodes, a malária continua sendo a que apresenta taxa mais elevada de infecção humana (KNUDSEN \& SLOOFF 1992). Em áreas da encosta da Serra do Mar distribuidas ao Sul do Estado de São Paulo, a situação epidemiológica mostra endemia baixa, com casos humanos esporádicos que se procura relacionar à intrusão de indivíduos gametóforos, oriundos das regiōes centro e norte do país (WANDERLEY 1985).

A questão vetorial local, bem como sua ocorrência em extensas áreas envolvendo os Estados do Paraná e Santa Catarina, tem indicado as populações de Anopheles(Kerteszia) cruzii e Anopheles (Kerteszia) bellator como diretamente envolvidas na transmissão. Ambas possuem caráter essencialmente silvestre, com predominância sazonal nas estações chuvosas, época quando o hábito antropófilo é nitidamente notado, e a busca ativa de hospedeiro pode alcançar distância de até 1.600 metros (CORREA 1961).

Os estudos sobre a dinâmica da composição populacional, em particular de An.cruzii, são ainda insuficientes para se ter espectro transparente do ciclo de vida de seus indivíduos. Nesse sentido, revestem-se de extrema importância epidemiológica as observações que procuram estimar a sobrevivência da população com vistas à comprovação mais definida de sua capacidade vetorial. Esta implica a mensuração de variáveis consideradas básicas, e classificadas dentro de dois grupos, a saber: a) estimativa da razão de inoculação, entendida como função da probabilidade de propagação e da conseqüente interação entre o parasita e a população hospedeira. b) determinação da probabilidade de transmissão entre hospedeiros, esta de natureza predominantemente entomológica, objetivando 
estimar a capacidade vetorial do transmissor. Para isso, surgiram modelos matemáticos, como o inicialmente proposto por MacDONALD (1957), e aprimorado por GARRETT-JONES (1964) e mais recentemente, recebendo novas sugestōes por parte de DYE (1986).

A identificação do conjunto populacional se faz através o reconhecimento da morte dos indivíduos distribuidos na população. E possível avaliar a produtividade populacional pela formação e sobrevivência dos indivíduos maduros e seu ingresso subseqüente no período reprodutivo (FORATTINI 1992). Neste caso, a estrutura populacional por idade, tem aplicação epidemiológica, face à contribuição que lhe é atribuida na determinação da capacidade vetorial de determinada população. MILBY e REISEN (1989) consideraram a sobrevivência do vetor como parâmetro fundamental para estimá-la. $E$ isso porque determina o tamanho populacional que é potencialmente capaz de transmitir a infecção e, também, prevê a duração média da vida infectiva do vetor. Ao mesmo tempo MUTERO e BIRLEY (1987), relatam que o conhecimento do intervalo de oviposição serve como indicator da freqüência alimentar, ambos indispensáveis na determinação da capacidade vetorial.

Assim sendo, a composição etária das fêmeas de mosquitos não deixa de constituir parâmetro relevante de sua eficácia epidemiológica. Além do mais, se a cada repasto sangüíneo obtido, nova ojportunidade surge entre mosquito/ agente, a importância do emprego da idade cresce, com o aumento da idade fisiológica. No entanto é reconhecida a complexidade das variaçōes inter e intrapopulacionais, daí ser difícil reconhecer a ação individual de vários fatores que atuam sobre as várias idades, de modo que a mortalidade se torne equivalente nos diferentes grupos etários (FORATTINI 1962). Embora o interesse para a determinação desse fator 
tenha feito com que vários métodos fossem preconizadas, atualmente a orientação predominante vem a ser a de verificar as características relacionadas com o aparelho reprodutor feminino.

Assim é que, a presença de ovos maduros retidos nos ovários (HITCHCOCK 1968) o tamanho da ampola do ovário e as alterações qualitativas da sua estrutura (MER 1932 e Polovodova 1941 apud DETINOVA 1962) e o exame das condições do sistema traqueal ovariolar (DETINOVA 1962) são características que permitem distinguir fêmeas nulíparas das oníparas. Os filamentos traqueolares ovarianos sofrem alterações irreversíveis após a primeira oviposição. Estes, nas fêmeas nulíparas ou recém-emersas, apresentam-se enrolados em forma de novelo, ao passo que nas oníparas, que tiveram os seus ovários desenvolvidos apresentam-se desenrolados, formando rede de finas traquéias e traquéolas. Apesar disso assinala-se a existência de condição intermediária observada por vários autores, na qual poucos filamentos traqueolares apresentam-se desenrolados, o que provavelmente indica que poucos ovos se desenvolveram. Isso se deve, talvez, a fêmeas autógenas ou com alimentação sangüínea incompleta (SERVICE 1976). São bastante utilizadas as observaçōes sobre os referidos filamentos, objetivando determinar a proporção de fêmeas oníparas de uma população, uma vez que a técnica de disseç̧ão é relativamente simples e segura, permitindo examinar grande número de exemplares.

A determinação da Idade Fisiológica com maior eficiência, mostrando o grau de paridade só se torna possível mediante a evidenciação das pequenas dilatações no tubo folicular do ovaríolo conseqüentes à passagem do ovo maduro pelo oviduto (Polovodova 1949; Detinova 1949 apud SERVICE 1976). Em conseqüência, a cada dilatação formada, corresponde uma oviposição em ciclo 
gonotrófico com desenvolvimento normal. As modificações dos ovariolos, o processo da formação das dilatações e a técnica de dissecção para estas observações foram descritas por vários autores (DETINOVA 1962; FORATTINI 1962; SERVICE 1976; CHARLWOOD 1980).

Alguns encontraram dificuldade em aplicar esta técnica para certas espécies de mosquitos, outros não encontraram esta mesma dificuldade para as mesmas espécies em outras localidades. BELLAMY e COBERT (1973) encontraram fêmeas de Culex tarsalis com dilatação ovariana sendo estas nulíparas, isto devido à reabsorção dos ovos. NAYAR e KNIGHT (1981) estudaram o grau de paridade em Culex nigripalpus criados em laboratório e constataram o aparecimento de 1 a 3 dilatações "aberrantes" em fêmeas nulíparas. Esses mesmos autores relatam que ROSAY (1969) encontrou tais dilatações em fêmeas anautógenas de Culex pipiens quinquefasciatus, $C x$ tarsalis e Culiseta inornata, sem nunca terem recebido alimentação sangüínea, e isso provavelmente devido à contínua formação de folículo pelo germário. Em Anopheles e muitas espécies de Aedes isso não ocorre, uma vez que a formação dos folículos.cessa logo após o primeiro folículo atingir o estágio II de Christophers e Mer, até sèr estimulado novamente através de um repasto sangüíneo. 


\section{Estado atual e objetivo}

Levando em consideração os aspectos mencionados, foram realizados estudos, em condições naturais e laboratoriais, principalmente com populações africanas e asiáticas implicadas na transmissão da malária, com valiosas contribuições epidemiológicas, especialmente para as espécies de grande importância vetorial. No entanto, em que pese a existência de destacados vetores de malária nas Américas, e em particular no Brasil, as investigações sobre a idade fisiológica, paridade e sobrevivência dessas populaçōes são escassas, em especial modo no que se refere às populaçōes do subgênero Kerteszia.

No que concerne a esses anofelinos, há que se mencionar observações levadas a efeito com Ancruzii na região de Paranaguá, Estado do Paraná e na do vale do Ribeira, Estado de São Paulo (LUZ e col. 1979; BARATA 1988), além das realizadas com Anneivai no município de Istmina, Costa Pacífica da Colômbia (ASTAIZA e col. 1988).

Como se pode ver, existe a necessidade de se obter informações mais completas a respeito dessas populações. $\mathrm{E}$ isso com o precípuo objetivo de avaliar a potencialidade vetora, passível de ser utilizada para orientação da vigilância epidemiologica.

Posto isso, decidiu-se por levar a efeito ensaios iniciais, propiciados por dados já existentes relatados por BARATA (1988). Assim sendo, escolheu-se a mesma área que serviu às observações dessa autora. Com os dados obtidos, objetiva-se que possam servir para o prosseguimento de estudos sobre a longevidade 
desses mosquitos. O relato da experiência piloto, constitui o objetivo da presente dissertação. 
MATERIAL E MÉTODO 
Como se referiu, o local escolhido para a realização das atividades de campo foi a Fazenda Folha Larga, situada no munićpio de Cananéia na região do Vale do Ribeira. Representa área cuja vegetaçáo corresponde a da mata da planície quaternária, com alguns sinais de atividade antrópica. A descrição pormenorizada de suas características, foi feita por FORATTINI e col. (1986).

A escolha desse local para estas observações, decorreu de alguns fatores precedentes conhecidos, entre os quais ressalta a elevada densidade populacional de $A n$. cruzii ao lado de notável riqueza de bromeliáceas epífitas e terrestres.

\section{I - Procedimento em Campo}

\section{Formas adultas}

As capturas tiveram início em janeiro de 1991, tendo se prolongado até abril de 1991, totalizando 4 meses, período este de maior densidade da população alvo (FORATTINI 1986). Foram realizadas nos períodos de atividade hematófaga mais intensa, isto é o correspondente ao crepúsculo vespertino, das 18:30 às 19:30 horas e ao matutino, das 8:00 as 9:00 horas. Os pontos de captura escolhidos foram: mata, margem da mata e o peridomicilio, distando entre si 200 e 350 metros, respectivamente.

$\mathrm{Na}$ mata as capturas foram feitas em dois níveis, correspondentes ao solo e à copa arbórea. Para isso, foi escolhida árvore cujas ramificaçōes superiores 
auxiliaram na construção de plataforma cerca de 15 metros de altura, acessível mediante escada construida ao longo de seu tronco. No solo, as capturas foram feitas sob pequena cobertura, construida com a finalidade de proteger o coletor, assim como o material coletado. Este ponto encontrava-se à 30 metros da árvore onde ocorreram as capturas da copa.

Adjacente à mata, havia área modificada pelo desmatamento e utilizada como pastagem bovina. Nesta área, na extremidade oposta a mata, havia um único domićlio e alguns anexos para animais domésticos Este foi utilizado para as capturas peridomiciliares.

A técnica utilizada nas coletas foi a isca humana, auxiliada por pequeno aspirador manual, com o intuito de coletar todos os mosquitos que pousavam ou que se aproximavam do indivíduo coletor para sugar.

Somente no período vespertino foram feitas capturas em todos os pontos anteriormente mencionados, enquanto que no período matutino as capturas envolveram apenas à mata e sua margem, visto que a dispersão diurna de $A n$ cruzii em ambiente aberto não tem sido assinalada.

\section{Formas imaturas}

As coletas tiveram início no final do mês de junho/1991 estendendose até o mês seguinte, totalizando quatro coletas. Estas foram feitas em criadouros naturais, a maioria em bromélias terrestres e raramente epífitas as quais, quando utilizadas, tiveram altura máxima de 2 metros. 
A cada coleta procedia-se à retirada de toda água existente no imbricamento das folhas da bromélia, juntamente com detritos orgânicos, para posterior exame. Assim sendo, todas as formas imaturas presentes foram colhidas.

A manutenção dessa mesma água por período de aproximadamente 10 dias, possibilitou eventual eclosão dos ovos possivelmente presentes nesse material. 


\section{II - Procedimentos em Laboratório}

\section{Formas adultas}

\subsection{Adultos capturados no campo}

Todos os mosquitos capturados vivos eram transportados em gaiolas, (40 cm de comprimento, $30 \mathrm{~cm}$ de largura e $30 \mathrm{~cm}$ de altura) até o laboratório do Posto de Pariquera-Açú, onde eram mortos e feita a triagem e contagem dos indivíduos pertencentes à espécie An.cruzii. Em seguida uma amostra era separada aleatoriamente e conservada em refrigerador até o momento da dissecção, para verificar a condição de paridade através das técnicas de Detinova e Polovodova e o estágio de desenvolvimento dos folículos, segundo CHRISTOPHERS (1911) e MER (1936). Todo material foi examinado no prazo máximo de 24 horas.

\subsection{Adultos criados em laboratório}

As formas imaturas coletadas no campo originaram adultos que foram alimentados com uma solução de mel em concentração aproximada de 5\%, por período que variou de 2 a 3 dias, em seguida ao qual foi oferecida às fêmeas um repasto sangüíneo humano. Tomou-se o cuidado de observar se o repasto se completou ou não, mediante o grau de distensão do abdomem e do abandono espontâneo da fonte alimentar. Para essas observações foram consideradas somente as fêmeas com repasto completo, isto é, o abdomem totalmente distendido e subseqüente à eliminação de gota hialina através do orifício anal. $O$ oferecimento 
do repasto sangüíneo ocorreu apenas uma vez, com exceção de uma única fêmea que recebeu um segundo repasto.

Todas as fêmes assim alimentadas foram submetidas a cópula induzida e colocadas individualmente em borréis (de $9 \mathrm{~cm}$ de altura e $4 \mathrm{~cm}$ de diâmetro) previamente preparados, com o fundo forrado com chumaço de algodão umedecido, sobre o qual se colocou rodela de papel de filtro, estando a boca fechada com pedaço de gaze presa com elástico. Assim, as fêmeas foram deixadas dentro de estufa onde a temperatura variou de 19 a $25^{\circ} \mathrm{C}$. Diariamente era feito o exame para verificar se estavam vivas ou mortas e as possíveis posturas. Todas as fêmeas mortas durante o experimento foram dissecadas, cujo tempo pós-morte, nunca ultrapassou intervalo superior a 24 horas.

As fêmeas foram dissecadas segundo a técnica já mencionada, com o objetivo de observar o seu desenvolvimento folicular assim como a sobrevivência em dias, com um único repasto sangüíneo. 


\section{2 - Desenvolvimento das formas imaturas}

Todas as larvas procedentes do campo foram distribuidas em bacias brancas de porte médio, $(17,5 \mathrm{~cm}$ de diâmetro superior, $12,5 \mathrm{~cm}$ a inferior e $7 \mathrm{~cm}$ de profundidade) mantendo-se o número máximo de 50 larvas por recipiente e, quando possível, agrupadas no mesmo.estágio de desenvolvimento.

As larvas foram alimentadas com ração básica para peixes tropicais (Alcon-Basic) finamente triturada, na proporção de aproximadamente $0,02 \mathrm{~g}$ para $400 \mathrm{ml}$ de água, mais algumas gotas de "Yogurt" natural dissolvido na água. Além disso, como foi utilizada água destilada, houve a necessidade de acrescentar sal (cloreto de sódio) na proporção de $0,14 \mathrm{~g}$ para $400 \mathrm{ml}$ de água.

Embora as necessidades alimentares sejam diferentes para cada estágio larvário, a quantidade de alimento servido foi padronizado para o experimento, com base no volume de água, número de larvas por vasilha e a quantidade de nutrientes.

Toda criação foi feita à temperatura ambiente do laboratório que oscilou entre 16 e $26^{\circ} \mathrm{C}$.

Tanto a mortalidade diária como o período de desenvolvimento larvário foram observados e devidamente registrados. 


\section{RESULTADOS}




\section{I - Observaçăo de Campo (Adultos)}

Durante quatro meses de captura com ritmo e método já descrito, foram capturados 3.748 An.cruzii (Tabela 1).

Com relação à paridade os resultados obtidos para um total de 631 fêmeas dissecadas, consta da Tabela 2, onde se observa que 90,49\% foram nulíparas e 9,50\% uníparas. Não foi assinalada nenhuma bípara na amostra examinada, o que significa que esse último coeficiente representou a paridade geral para essa espécie. 
Tabela 1.

Resultado global das capturas para An. cruzii na Fazenda Folha Larga, município de Cananéia, no período de janeiro a abril de 1991, nos ambientes extradomiciliar e peridomiciliar.

\begin{tabular}{lcc}
\hline Ambiente & Pontos de Captura & An.cruzii \\
\hline & Mata Copa & 1.703 \\
Extradomiciliar & Mata Solo & 697 \\
& Margem Mata & 1.145 \\
\hline Peridomiciliar & & 203 \\
\hline TOTAL & & 3.748 \\
\hline
\end{tabular}

Das 631 fêmeas dissecadas, $79,09 \%$ e $20,9 \%$ foram do ambiente extradomiciliar e peridomiciliar, respectivamente. 
Tabela 2.

Resultado global quanto à paridade das fêmeas de $A n$. cruzii capturadas na Fazenda Folha Larga, município de Cananéia, no período de janeiro a abril de 1991 nos dois ambientes.

\begin{tabular}{|c|c|c|c|c|}
\hline Ambiente & $\begin{array}{l}\text { Pontos de } \\
\text { Captura }\end{array}$ & $\begin{array}{c}\mathrm{N}^{\circ} \\
\text { Dissecado }\end{array}$ & $\begin{array}{c}\mathrm{N}^{\circ} \\
\text { Nulíparas }\end{array}$ & $\begin{array}{c}\mathrm{N}^{\circ} \\
\text { Uníparas }\end{array}$ \\
\hline & Mata Copa & 234 & 216 & 18 \\
\hline Extrado- & Mata Solo & 127 & 110 & 14 \\
\hline miciliar & Margem Mata & 141 & 123 & 18 \\
\hline $\begin{array}{l}\text { Perido- } \\
\text { miciliar }\end{array}$ & & 132 & 122 & 10 \\
\hline TOTAL & & 631 & 571 & 60 \\
\hline
\end{tabular}

Nas Tabelas 3, 4 e 5 apresenta-se a distribuição da paridade e do desenvolvimento folicular segundo Christophers e Mer, levando-se em conta o ambiente extradomiciliar nas situações correspondentes à Mata Copa, Mata Solo e Margem da Mata, no período vespertino das 18:30 às 19:30 horas, os meses de captura e o número total coletado e examinado. 
Os resultados das capturas para os mesmos locais, porém no horário matutino, das 08:00 às 09:00 horas, estão contidos nas Tabelas 6, 7 e 8.

Tabela 3.

Resultado quanto à paridade e o estágio do desenvolvimento folicular segundo Christophers e Mer das fêmeas de An. cruzii capturadas, local Mata copa no período vespertino, na Fazenda Folha Larga, município de Cananéia, nos meses de janeiro a abril de 1991.

\begin{tabular}{|c|c|c|c|c|c|c|c|c|c|c|}
\hline \multirow[t]{2}{*}{ Data } & \multirow{2}{*}{$\begin{array}{c}\mathrm{N}^{\circ} \\
\text { Capturado }\end{array}$} & \multirow{2}{*}{$\begin{array}{c}\mathrm{N}^{\circ} \\
\text { Dissecado }\end{array}$} & \multicolumn{4}{|c|}{ Nul íparas } & \multicolumn{4}{|c|}{ Uníparas } \\
\hline & & & I e II & 11 & 111 & Total & I e 11 & II & III & Total \\
\hline $21 / 1$ & 290 & 29 & 15 & 9 & 3 & 27 & $\cdot$ & 2 & $\cdot$ & 2 \\
\hline $19 / 2$ & 422 & 40 & 14 & 19 & 3 & 36 & - & 4 & - & 4 \\
\hline $12 / 3$ & 334 & 34 & 4 & 24 & 6 & 34 & - & - & $\cdot$ & 0 \\
\hline $9 / 4$ & 497 & 48 & 8 & 32 & $\cdot$ & 40 & - & 3 & 5 & 8 \\
\hline TOTAL & 1.543 & 151 & 41 & 84 & 12 & 137 & - & 9 & 5 & 14 \\
\hline
\end{tabular}


Tabela 4.

Resultado quanto à paridade e o estágio do desenvolvimento folicular segundo Christophers e Mer das fêmeas de An. cruzii capturadas, local Mata Solo no período vespertino, na Fazenda Folha Larga, município de Cananéia, nos meses de janeiro à abril de 1991.

\begin{tabular}{|c|c|c|c|c|c|c|c|c|c|c|}
\hline \multirow{2}{*}{ Data } & \multirow{2}{*}{$\begin{array}{c}\mathrm{N}^{\circ} \\
\text { Capturado }\end{array}$} & \multirow{2}{*}{$\begin{array}{c}N^{\circ} \\
\text { Dissecedo }\end{array}$} & \multicolumn{4}{|c|}{ Nul f́paras } & \multicolumn{4}{|c|}{ Uniparas } \\
\hline & & & $I$ e II & II & III & Total & $1 e 11$ & 11 & III & Total \\
\hline $21 / 1$ & 113 & 12 & 4 & 4 & 1 & 9 & 1 & 2 & - & 3 \\
\hline $19 / 2$ & 233 & 24 & 10 & 9 & 4 & 23 & - & 1 & $\cdot$ & 1 \\
\hline $12 / 3$ & 152 & 16 & 5 & 9 & 2 & 16 & - & $\cdot$ & - & 0 \\
\hline $9 / 4$ & 116 & 12 & $\cdot$ & $\cdot$ & 7 & 7 & $\cdot$ & 1 & 4 & 5 \\
\hline TOTAL & 614 & 64 & 19 & 22 & 14 & 55 & 1 & 4 & 4 & 9 \\
\hline
\end{tabular}


TABELA 5

Resultado quanto à paridade e o estágio do desenvolvimento folicular segundo Christophers e Mer das fêmeas de An.cruzii capturadas, local Margem da Mata no período vespertino, na Fazenda Folha Larga, município de Cananéia, nos meses de janeiro à abril de 1991.

\begin{tabular}{|c|c|c|c|c|c|c|c|c|c|c|}
\hline \multirow[t]{2}{*}{ Data } & \multirow{2}{*}{$\begin{array}{c}N^{\circ} \\
\text { Capturado }\end{array}$} & \multirow{2}{*}{$\begin{array}{c}N^{\circ} \\
\text { Dissecado }\end{array}$} & \multicolumn{4}{|c|}{ Nul ípares } & \multicolumn{4}{|c|}{ Unfparas } \\
\hline & & & $I$ e II & 11 & III & Total & I e II & 11 & $I I I$ & Total \\
\hline $21 / 1$ & 93 & 10 & 2 & 4 & 1 & 7 & - & 3 & - & 3 \\
\hline $19 / 2$ & 311 & 27 & 1 & 18 & 5 & 24 & - & 2 & 1 & 3 \\
\hline $12 / 3$ & 564 & 54 & 7 & 18 & 24 & 49 & - & 2 & 3 & 5 \\
\hline $9 / 4$ & 138 & 14 & 6 & 3 & 1 & 10 & - & 1 & 3 & 4 \\
\hline TOTAL & 1.106 & 105 & 16 & 43 & 31 & 90 & - & 8 & 7 & 15 \\
\hline
\end{tabular}




\section{Tabela 6.}

Resultado quanto à paridade e o estágio do desenvolvimento folicular segundo Christophers e Mer das fêmeas de An.cruzii capturadas, local Mata Copa no período matutino, na Fazenda Folha Larga, município de Cananéia, nos meses de janeiro a abril de 1991.

\begin{tabular}{|c|c|c|c|c|c|c|c|c|c|c|}
\hline \multirow[t]{2}{*}{ Data } & \multirow[b]{2}{*}{ Capturado } & \multirow[b]{2}{*}{ Dissecado } & \multicolumn{4}{|c|}{ Nul íparas } & \multicolumn{4}{|c|}{ Uníparas } \\
\hline & & & I e II & II & III & Total & I e II & II & 111 & Total \\
\hline $23 / 1$ & 15 & 14 & - & 7 & 2 & 9 & 1 & 3 & 1 & 5 \\
\hline $21 / 2$ & 25 & 25 & 7 & 12 & 3 & 22 & - & 3 & - & 3 \\
\hline $13 / 3$ & 4 & 4 & 1 & 3 & - & 4 & - & - & - & 0 \\
\hline $9 / 4$ & 116 & 30 & 13 & 11 & 6 & 30 & - & - & - & 0 \\
\hline TOTAL & 160 & 73 & 21 & 33 & 11 & 65 & 1 & 6 & 1 & 8 \\
\hline
\end{tabular}


Tabela 7.

Resultado quanto à paridade e o estágio do desenvolvimento folicular segundo Christophers e Mer das fêmeas de An.cruzii capturadas, local Mata Solo no período matutino na Fazenda Folha Larga, município de Cananéia, nos meses de janeiro à abril de 1991.

\begin{tabular}{|c|c|c|c|c|c|c|c|c|c|c|}
\hline \multirow{2}{*}{ Data } & \multirow{2}{*}{$\begin{array}{c}\mathrm{N}^{\mathrm{O}} \\
\text { Capturado }\end{array}$} & \multirow{2}{*}{$\begin{array}{c}\mathrm{N}^{\circ} \\
\text { Dissecado }\end{array}$} & \multicolumn{4}{|c|}{ Nul fparas } & \multicolumn{4}{|c|}{ Uníparas } \\
\hline & & & I e II & II & III & Total & $1 \in I 1$ & $I I$ & 111 & Total \\
\hline $23 / 1$ & 14 & 12 & 1 & 6 & 2 & 9 & - & 3 & $\cdot$ & 3 \\
\hline $21 / 2$ & 32 & 30 & 12 & 13 & 4 & 29 & 1 & - & - & 1 \\
\hline $13 / 3$ & 3 & 3 & 1 & 2 & - & 3 & - & - & - & 0 \\
\hline $9 / 4$ & 34 & 11 & 1 & 8 & 1 & 10 & - & 1 & $\cdot$ & 1 \\
\hline TOTAL & 88 & 56 & 15 & 29 & 7 & 51 & 1 & 4 & 0 & 5 \\
\hline
\end{tabular}


Tabela 8.

Resultado quanto à paridade è o.estâgio do desenvolvimento folicular segundo Christophers e Mer das fêmeas de Aṇ. cruzii capturadas, local Margem da Mata no período matutino na Fazenda Folha Larga, município de Cananéia, nos meses de janeiro à abril de 1991.

\begin{tabular}{|c|c|c|c|c|c|c|c|c|c|c|}
\hline \multirow[t]{2}{*}{ Deta } & \multirow{2}{*}{$\begin{array}{c}N^{\circ} \\
\text { Capturado }\end{array}$} & \multirow{2}{*}{$\begin{array}{c}N^{\circ} \\
\text { Dissecado }\end{array}$} & \multicolumn{4}{|c|}{ Mul fparas } & \multicolumn{4}{|c|}{ Unipares } \\
\hline & & & 1 e 11 & II & 111 & Total & $I$ e II & II & III & Total \\
\hline $23 / 1$ & 11 & 11 & 3 & 6 & 2 & 11 & - & - & - & 0 \\
\hline $21 / 2$ & 7 & 7 & 3 & 4 & $\cdot$ & 7 & $\cdot$ & $\cdot$ & $\cdot$ & 0 \\
\hline $13 / 3$ & 6 & 6 & 3 & 1 & 1 & 5 & - & 1 & $\cdot$ & 1 \\
\hline $9 / 4$ & 15 & 5 & 1 & 2 & - & 3 & 2 & - & - & 2 \\
\hline TOTAL & 39 & 29 & 10 & 13 & 3 & 26 & 2 & 1 & 0 & 3 \\
\hline
\end{tabular}

Os resultados das capturas de fêmeas levadas a efeito no periodomícilio com as respectivas dissecções, segundo os meses de coleta e o grau de paridade constam na Tabela 9. Neste caso o horário das coletas foi exclusivamente no período vespertino, isto é, das 18:30 às 19:30 horas. 
Tabela 9.

Resultado quanto à paridade e o estágio de desenvolvimento folicular segundo Christophers e Mer das fêmeas de An. cruzii capturadas no peridomicilio, no período vespertino na Fazenda Folha Larga, município de Cananéia, nos meses de janeiro à abril de 1991.

\begin{tabular}{|c|c|c|c|c|c|c|c|c|c|c|}
\hline \multirow{2}{*}{ Data } & \multirow{2}{*}{$\begin{array}{c}\mathrm{N}^{\mathrm{O}} \\
\text { Capturado }\end{array}$} & \multirow{2}{*}{$\begin{array}{c}\mathrm{N}^{\circ} \\
\text { Dissecado }\end{array}$} & \multicolumn{4}{|c|}{ Mul íparas } & \multicolumn{4}{|c|}{ Uniparas } \\
\hline & & & I e II & II & III & Total & I e II & II & III & Total \\
\hline $21 / 1$ & 18 & 17 & 5 & 9 & 3 & 17 & - & - & $\cdot$ & 0 \\
\hline $19 / 2$ & 24 & 24 & 2 & 17 & 3 & 22 & - & 1 & 1 & 2 \\
\hline $12 / 3$ & 19 & 18 & 7 & 3 & 6 & 16 & - & 2 & - & 2 \\
\hline $9 / 4$ & 142 & 68 & 27 & 30 & 5 & 62 & $\cdot$ & 5 & 1 & 6 \\
\hline TOTAL & 203 & 127 & 41 & 59 & 17 & 117 & - & 8 & 2 & 10 \\
\hline
\end{tabular}




\section{II - Observaçóes de Laboratório}

\section{Período de desenvolvimento das formas imaturas}

O material utilizado foi procedente de cerca de 600 . bromélias, na maioria terrestres e algumas epífitas. O número total de formas imaturas coletadas atingiu 1.158, incluindo ovos, larvas de vários estádios e pupas. A Tabela 10 mostra estas informaçōes.

Tabela 10.

Resultado das coletas das formas imaturas, de An.cruzii, bromélias segundo o estágio de desenvolvimento. Fazenda Folha Larga, município de Cananéia nos meses de junho e julho de 1991.

\begin{tabular}{lccccc}
\hline Data de & \multicolumn{2}{c}{ Estágio de desenvolvimento } & Total \\
\cline { 2 - 5 } Coleta & ovo $+\mathrm{L}_{1}$ & $\mathrm{~L}_{2}+\mathrm{L}_{3}$ & $\mathrm{~L}_{4}$ & Pupa & \\
\hline $25 / 6$ & 350 & 100 & 44 & 7 & 501 \\
$2 / 7$ & 59 & 34 & 33 & 3 & 129 \\
$15 / 7$ & 230 & 90 & 69 & 3 & 392 \\
$30 / 7$ & 100 & 36 & 0 & 0 & 136 \\
\hline TOTAL & 739 & 260 & 146 & 13 & 1.158 \\
\hline
\end{tabular}


O período de desenvolvimento larvário, sob condiçōes experimentais foi de aproximadamente $\mathbf{4 0}$ dias, considerando-se a partir de larvas recém-eclodidas. Neste período a mortalidade das formas imaturas foi de 8,29\% para larvas (96 larvas) e 1,98\% para pupas (23 pupas).

\section{Desenvolvimento de formas adultas}

Obteve-se 308 fêmeas que foram mantidas em condiçōes de laboratório, alimentadas com solução de mel na concentração aproximada de 5\% por 2 a 3 dias. Após esse período, 283 exemplares foram alimentados com sangue humano apenas uma vez, com a finalidade de se acompanhar o tempo necessário para o desenvolvimento folicular de acordo com o critério de Christophers e Mer, além das possíveis oviposiçōes (Tabela 11).

Dessas fêmeas somente 44 conseguiram atingir a primeira postura, no total de 1.371 ovos (Tabela 12).

O lote representado pelas 25 fêmeas restantes, teve seus componentes separados e mantidos com solução de mel, objetivando-se observar o que ocorreria com o seu desenvolvimento folicular na ausência de alimentação sangüínea. 
Tabela 11.

Resultado do tempo em dias para o desenvolvimento folicular de An.cruzii segundo Christophers e Mer.

\begin{tabular}{|c|c|c|c|c|c|c|}
\hline Dias & $I$ e II & III & IV & $\mathrm{V}$ & Oviposição & Total \\
\hline 1 & 2 & 3 & - & - & - & 5 \\
\hline 2 & 1 & 4 & 5 & - & - & 10 \\
\hline 3 & 7 & 3 & 6 & - & - & 16 \\
\hline 4 & 2 & 11 & 2 & 12 & 2 & 29 \\
\hline 5 & 4 & 10 & 2 & 29 & 4 & 49 \\
\hline 6 & - & 25 & - & 33 & 14 & 72 \\
\hline 7 & - & 16 & - & 13 & 20 & 49 \\
\hline 8 & - & 19 & - & 8 & 3 & 30 \\
\hline 9 & - & 15 & - & 2 & 1 & 18 \\
\hline 10 & - & 5 & - & - & - & 5 \\
\hline TOTAL & 17 & 111 & 15 & 97 & 44 & 283 \\
\hline
\end{tabular}


Tabela 12.

Observação do tempo de vida após alimentação sangüínea até a oviposição e o total de ovos das fêmeas de An.cruzii, criadas em laboratório.

Dias de sobrevida Número de fêmeas Total de ovos

\begin{tabular}{lcc}
\hline 4 & 2 & 32 \\
5 & 4 & 149 \\
6 & 14 & 469 \\
7 & 20 & 651 \\
8 & 3 & 28 \\
9 & 1 & 42 \\
\hline TOTAL & 44 & 1.371 \\
\hline
\end{tabular}

Uma única fêmea, já referida em material e métodos, conseguiu duas oviposiçōes após uma segunda alimentaçāo sangüínea ocorrida logo após a primeira oviposição. Esse resultado não consta da Tabela 12, uma vez que, obviamente, não tem representatividade. A primeira oviposição ocorreu após 8 dias com o total de 101 ovos e a segunda, após 18 dias com o total de 8 ovos. Essa fêmea foi dissecada, mas não foi possível observar a segunda dilatação pedicular. 
As 25 fêmeas que não receberam alimentaçăo sangüinea, não utrapassaram a fase II de Christophers e Mer. 
DISCUSSÃO E COMENTÁRIOS 
Este estudo preliminar feito com Anopheles cruzii, incluindo atividades de campo e de laboratório, objetivou obter maior conhecimento de alguns parâmetros entomológicos relevantes na avaliação da capacidade de transmissão da malária por parte dessa espécie.

$\mathrm{Na}$ epidemiologia das doenças transmitidas por vetores biológicos, foram realizados trabalhos na tentativa de combinar estes parâmetros, dentro de simples conceito de capacidade vetorial. Esta pode ser estimada conhecendo-se a freqüência e o hábito de picada sobre o homem, mais o fator de longevidade ou da expectativa de vida.

Segundo MacDONALD (1957) e GARRETT-JONES (1964) a capacidade vetorial (C.V.) pode ser expressa pela seguinte equação:

$$
C V=\frac{\mathrm{ma}^{2} \mathrm{p}^{\mathrm{n}}}{-\log _{\mathrm{e}} \mathrm{p}}
$$

onde:

$\mathrm{m}$ = densidade em relação ao homem

$\mathrm{a}=$ freqüência de picada $\mathrm{x}$ human blood index (HBI)

$$
E=\frac{p^{n}}{-\log _{e} p}
$$

onde:

$E$ = expectativa de vida ou fator de longevidade.

$\mathrm{p}=$ probabilidade de sobreviver por um dia.

$\mathrm{n}$ = duração do período de incubação extrínseco. 
Estimar a sobrevivência do vetor implica o conhecimento da duração do seu ciclo gonotrófico $(\mathrm{g})$ o qual é equivalente ao intervalo entre oviposiçōes. Isso engloba, necessariamente, o período. que vai desde a procura e o encontro do hospedeiro para sugar, a digestão do sangue ingerido, o desenvolvimento ovariano e, finalmente, a realização da postura. Para isso, pode-se lançar mão de procedimentos de laboratório e de campo.

No campo utiliza-se geralmente a técnica de marcação e recaptura, que consiste fundamentalmente em soltar fêmeas marcadas, coletá-las e examinálas para verificação do desenvolvimento ovariano. No laboratório, utiliza-se fêmeas de idade conhecida, obtidas de colônias ou de material criado, a partir de larvas coletadas em habitats naturais.

Como experiência piloto, procurou-se realizar a parte de laboratório, referente à duração do ciclo gonotrófico. Para tanto, coletou-se 1.158 larvas e ovos a partir de 600 bromélias, aproximadamente, o que forneceu número médio de 1,93 larvas por bromélia. Esta densidade larvária foi um tanto maior do que a encontrada por FORATTINI e col. (1961) na mesma regiāo, a qual foi de 0,26 larvas/bromélia. Ao mesmo tempo o esgotamento de todas as larvas durante 10 dias de observações, parece ter influenciado aquele resultado.

O período de desenvolvimento larvário em condiçōes de laboratório, foi relativamente longo, ou seja, de 40 dias aproximadamente. Isso se deveu talvez ao fato dessa espécie ser predominantemente silvestre e de difícil adaptação às condiçōes artificiais. Com An.(Ker.)neivai a duração do ciclo aquático foi de 28 a 35 dias em condições de laboratório (BAERG e MELVIN 1974). 
Dos adultos obtidos, somente 308 fêmeas prestaram-se às observações em questão. Todas as fêmeas que não receberam alimentação sangüinea, totalizando 25, apresentaram o primeiro folículo no estágio II de Christophers e Mer. Isso, provavelmente, pela falta de estímulo sangüíneo. As demais receberam um único repasto sangüíneo, dando-nos a oportunidade de observar e acompanhar todo o seu desenvolvimento folicular (Tabela 11).

A cópula induzida, foi realizada em todas as fêmeas observadas, mas infelizmente sem resultado positivo, isto é os ovos obtidos foram inférteis, não embrionados. As espermatecas não foram examinadas. Para estudo futuro há necessidade de aprimoramento desta técnica para essa espécie. E isso porque as fêmeas não fecundadas poderão vir a desenvolver os ovos normalmente, ou então desenvolvê-los em período de tempo maior, quando comparadas com as fertilizadas.

Para algumas espécies de Anopheles, como o An. subpictus a inseminação é pré-requisito para o desenvolvimento dos ovos, fenômeno este, denominado estímulo espermatogênico (ROY, 1940). Para An.cruzii os nossos dados demonstraram que a inseminação não pareceu ser pré-requisito absoluto, pois os ovos tiveram o seu desenvolvimento e maturação normais.

Das 283 fêmeas com alimentação sangüínea, 97 atingiram o estágio $V$ de Christophers e 44 chegaram até a postura, com uma média de 31,15 ovos por 
fêmea. Isso mostra que, praticamente, $50 \%$ das fêmeas conseguiram o seu desenvolvimento folicular completo com um único repasto sangüíneo, mas isso não permite ainda afirmar se existe ou não concordância gonotrofica. Com este resultado, podemos afirmar que o tempo médio gasto da alimentação sangüínea até a oviposição, foi de 6 a 7 dias, nas condições acima mencionadas. 
Curva de Sobrevivência das fêmeas de $A n$ cruzii criados em laboratório.

\section{SOBRE VIVENTES}

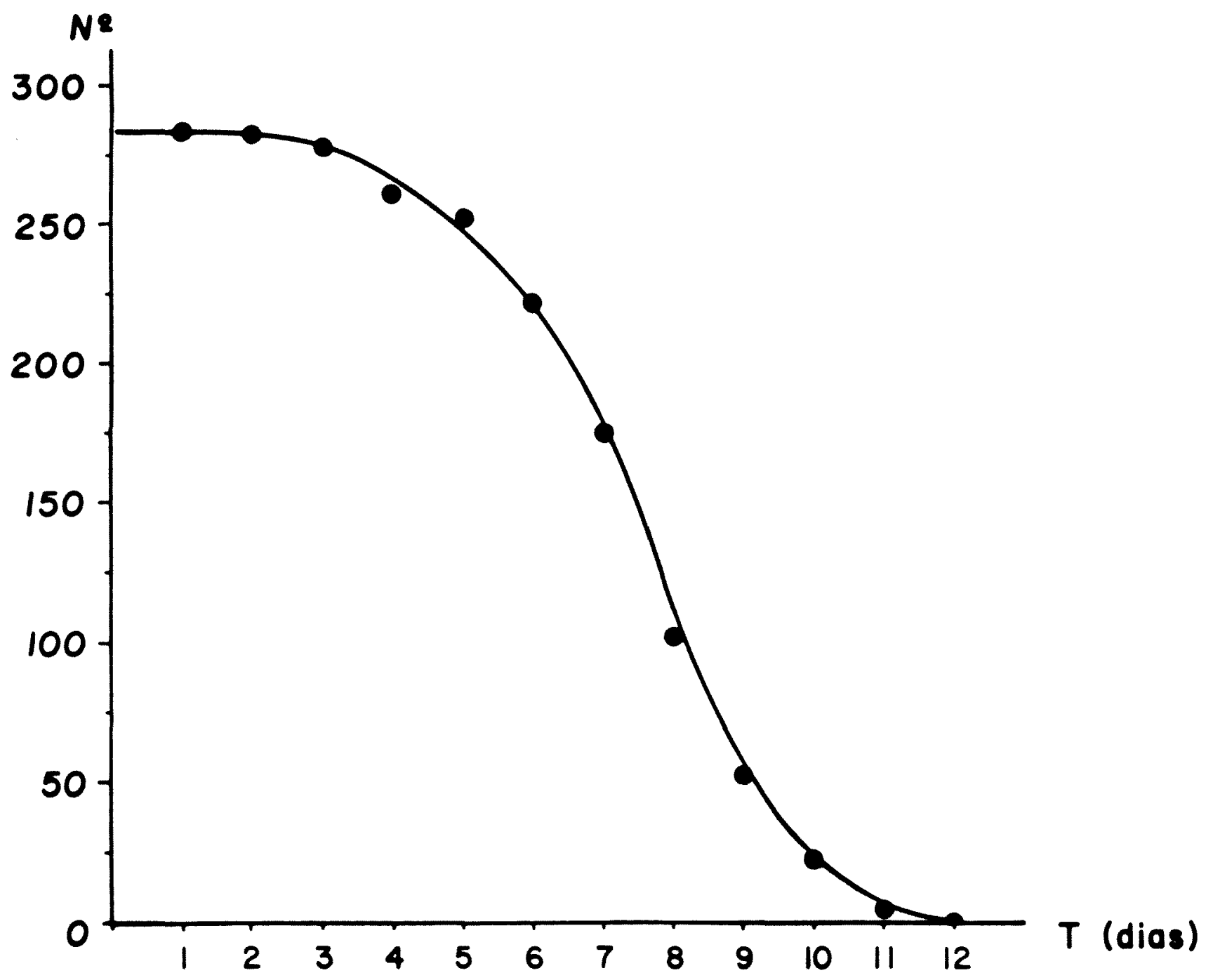

A curva de sobrevivência mostra que a mortalidade foi aproximadamente uniforme, no decorrer dos dias, com crescimento progressivo a partir do $6^{\circ}$ dia até o $12^{\circ}$ dia. 
Em condições naturais o período de sobrevivência foi bem maior para esta espécie de 35 a 56 dias segundo (FERREIRA e col. 1969).

Das atividades de campo, 3.748 fêmeas de $A n$. Ker) cruzii foram capturadas, 631 das quais foram dissecadas para as observações da paridade. Destas, $90,49 \%$ revelaram-se nulíparas e somente $9,50 \%$ uníparas, mostrando que a maior parte da população é constituida de indivíduos jovens. Muito diferente das populaçōes africanas de Angambiae e Anfunestus do nordeste da Tanzânia, onde foi possível encontrar fêmeas com até 14 oviposiçōes (GILLIES e WILKES, 1965). CHARLWOOD e WILKES (1979) estudando Andarlingi do norte de Mato Grosso, Brasil, encontraram fêmeas com até seis posturas.

Já para Ancruzii poucos estudos foram realizados neste particular. LUZ e col. (1979) estudando esta espécie no litoral paranaense encontraram 80\% de fêmeas nulíparas, $19 \%$ de uníparas e 0,16\% de bíparas. BARATA (1988) encontrou $75,99 \%$ de fêmeas nulíparas, $23,28 \%$ de uníparas e $0,74 \%$ de bíparas, no município de Cananéia, São Paulo.

Os resultados obtidos com estas observações que focalizaram o ambiente extra e peridomiciliar, nos diferentes períodos de captura (matutino e vespertino), mostraram que não houve diferença significativa quanto à proporção de fêmeas uníparas na população estudada.

Aspecto importante, que chamou atenção, foi a elevada porcentagem $( \pm 80 \%)$ de fêmeas nulíparas, apresentando os seus folículos no estágio II de 
Christophers, e pois indicando ser esta a primeira procura para alimentação sangüínea.

É possível que esta eșécie apresente razoável capacidade vetora, apesar da baixa longevidade, pois esta é provavelmente, compensada pela alta densidade ou pela variação na freqüência de picada.

Diante desses resultados, pode-se dispor de informações locais que se prestarão a nortear e interpretar as observações, a recém realizadas. Nesse particular interessará verificar o que segue:

1) Existência ou não de seleção no que concerne à paridade, para o ambiente intra, peri e extradomiciliar.

2) Estimativa da longevidade mediante o método da marcaçãosoltura-recaptura.

3) Estimativa da densidade populacional, mediante os resultados conseguidos com essa técnica.

Em vista disso, é de se considerar que os dados preliminares aqui apresentados trazem informaçōes gerais de interesse. Estas são consubstanciadas, como se referiu, na baixa paridade e alta densidade. 
REFERENCIAS BIBLIOGRÁFICAS 
ASTAIZA V.R.; MURILO, B.C.; FAJARDO, O.P. Biologia de Anopheles (Kerteszia) neivai H., D. \& k., 1913 (Diptera: Culicidae) en la costa Pacifica de Colombia. II Fluctuación de la población adulta. Rev. Saúde públ., S.Paulo, 22:101-8, 1988.

BAERG, D.C. \& MELVIN, M.B. Anopheles neivai Howard, Dyar \& Knab: Laboratory observations on the life cycle and description of the egg stage (Diptera: Culicidae). J. Med. Ent., 11,:629-30, 1974.

BARATA, E.A.M. de F. Idade fisiológica de Anopheles (kerteszia) cruzii Dyar e Knab, 1909 (Diptera: Culicidae) em populaçōes de campo no Município de Cananéia. São Paulo, 1988. [Dissertação de Mestrado - Instituto de Ciências Biológicas da USP].

BELLAMY, R.E. \& CORBET, P.S. Combined autogenous and anantogenous ovarian development in individual Culex tarsalis Coq. (Dipt., Culicidae). Bull. ent. Res., 63:335-46, 1973.

CHARLWOOD, J.D.; WILKES, T.T. Studies on the age-comparison of samples of Anopheles darlingi Root (Diptera: Culicidae) in Brazil. Bull. ent. Res., 69:33742, 1979.

CHARLWOOD, J.D.; RAFAEL, J.A.; WILKES, T.J. Métodos de determinar a idade fisiológica em Diptera de importância médica. Uma revisāo com especial referência aos vetores de doenças na América do Sul. Acta Amazonica, 10:311$33,1980$.

CHRISTOPHERS, S.R. The development of the egg follicle in Anophelines . Paludism., 2:73-8, 1911.

CORREA; R.R.; FORATTINI, O.P.; GUARITA, O.F.; RABELLO, E.X. Observaçōes sobre o vôo do Anopheles (Kerteszia) cruzii e do $A$. $(K)$ bellator, vetores de malária (Diptera, Culicidae). Arq. Hig. Saúde públ., 26:333-42, 1961. 
DETINOVA, T.S. Age grouping methods in Diptera of medical importance. Geneva, W.H.O. 1962. (WHO - Monograph series, 47).

DYE, C. Vectorial capacity: Must be measured all its components? Parasit. Today, 2:203-09, 1986.

FORATTINI, O.P.; CORREAA, R.R.; RABELLO, E.X.; GUARITA, O. Algumas observações sobre a densidade de Anofelinos Kerteszia no Estado de São Paulo, Brasil. Arq. Hig. Saúde públ., 262:46-56, 1961.

FORATTINI, O.P. Entomologia médica. São Paulo, Ed. USP, 1962. v.1.

FORATTINI, O.P.; GOMES, A. de C.; NATAL, D.; SANTOS, J.L.F. Observações sobre atividade de mosquitos Culicidae em matas primitivas da planície e perfis epidemiológicos de vários ambientes no Vale do Ribeira, São Paulo, Brasil. Rev. Saúde públ., S.Paulo, 20:178-203, 1986.

FORATTINI, O.P. Ecologia, Epidemiologia e Sociedade. São Paulo, Ed. USP, 1992.

GARRETT-JONES, C. The human blood index of malaria vectors in relation to epidemiological assessment. Bull Wld Hlth Org., 30:241-61, 1964.

GILLIES, By M.T. and WILKES, T.J. A study of the age-composition of populations of Anopheles gambiae Giles and $A$. funestus Giles in NorthEastern Tanzania. Bull. ent. Res., 52:237-62, 1965.

HITCHCOCK Jr., J.C. Egg-retention in Anopheles quadrimaculatus Say in relation to physiological age. J. med. Ent., 5: 8, 1968.

KNUDSEN, A.B. \& SLOOFF, R. Vector-borne disease problems in rapid urbanization: new approaches to vector control. Bull Wld Hith Org., 70:1-6, 1992. 
LUZ, E.; CONSOLIM, J.; VIEIRA, A.M.; BORBA, A.M. Alguns aspectos epidemiológicos da persistência da transmissão de malária no litoral paranaense. Idade Fisiológica de Anopheles cruzii (Diptera, Culicidae). Arq. Biol Tecnol., 22:63-88, 1979.

MacDONALD, G. The epidemiology and control of malaria. London, Oxford Univ. Press, 1957.

MER, G.G. Experimental study on the development of the ovary in Anopheles elutus, Edw. (Dipt. Culic.). Bull. ent. Res., 27:351-9, 1936.

MILBY, M.M. \& REISEN, W.K. Estimation of vectorial capacity: Vector survivorship. Bull. Soc. Vector Ecol, 14:47-54, 1989.

MUTERO, C.M. \& BIRLEY, M.H. Estimation of the survival rate and oviposition cycle of field populations of malaria vectors in Kenya. J. appl. Ecol, 24:853-63, 1987.

NAYAR, J.K. \& KNIGHT, J.W. Occurrence of ovariolar dilatations in nulliparous mosquitoes: Culex nigripalpus. Mosq. News, 41:281-7, 1981.

ROY, D.N. Influence of spermathecal stimulation on the Physiological Activities of Anopheles subpictus. Nature, 145:747-8, 1940.

SERVICE, M.W. Mosquito Ecology, Field sampling methods. London, Applied Science Publishers, 1976.

WANDERLEY, D.M.V.; ANDRADE, J.C.R. de; MENEGUETTI, L.C.; CHINELATTO, M.J.; DUTRA, A.P. Malária no Estado de São Paulo, Brasil, 1980 a 1983. Rev. Saúde públ., S.Paulo, 19: 28-36, 1985. 